\title{
Individual differences in bridging inference processes
}

\author{
MURRAY SINGER, PETER ANDRUSIAK, PAUL REISDORF, and NANCY L. BLACK \\ University of Manitoba, Manitoba, Winnipeg, Canada
}

\begin{abstract}
The role of individual differences in bridging-inference processing was studied. Students $(n=$ 135) read passages of short to moderate length. After each one, they answered corresponding questions about inferences that bridged causally related ideas that were either near or far apart in the text. The main hypothesis was that local bridging-inference processing is facilitated by the reader's predisposition to access pertinent knowledge during comprehension. Regression analyses provided support for this proposal and indicated that greater working-memory capacity and vocabulary knowledge promote inference processing. The following relationships between the predictors and inference processing were proposed: Knowledge access promotes the co-occurrence in working memory of the text ideas and knowledge needed to compute the bridge. Workingmemory capacity enhances the likelihood that needed antecedent ideas will be available to the bridging processes. Vocabulary knowledge may promote inference processing because unfamiliar word meanings place more demands on working-memory resources than do familiar meanings.
\end{abstract}

The present study was undertaken to examine individual differences in text inference processes. Particular emphasis was placed on inferences that provide connections, or bridges (Haviland \& Clark, 1974), among the propositions underlying discourse. A bridging inference is needed when the understander cannot retrieve a referent for the given information of the current sentence from either working memory or long-term memory (LTM; see Haviland \& Clark, 1974; Kintsch \& van Dijk, 1978).

Bridging inferences, accordingly, contribute to message coherence. Consider Example 1:

1. The spy quickly threw his report in the fire. The ashes floated up the chimney.

This sequence includes no referent for the given argument of the second sentence, ashes. The sequence will appear sensible, however, if it is inferred that the report burned to ashes. Without such a bridge, in contrast, this sequence would seem as disjointed as: "The spy quickly threw his report in the fire. The ice cream floated up the chimney."

Evidence that bridging inferences frequently accompany discourse comprehension stems from numerous on-line and memory measures of comprehension (e.g., Bloom, Fletcher, van den Broek, Reitz, \& Shapiro, 1990; Fletcher,

\footnotetext{
This research was supported by Grant A9800 from the Natural Sciences and Engineering Research Council of Canada to the first author. The data of the first sample described in the experiment were presented at the meeting of the Psychonomic Society, Atlanta, November, 1989. We are grateful to Peter Dixon, Joanne LeFevre, Mike Masson, and Tom Trabasso, who provided valuable insights about this research. $N$. Black is now at the University of North Dakota. Requests for reprints should be addressed to $M$. Singer, Department of Psychology, University of Manitoba, Winnipeg R3T 2N2, Canada.
}

Hummel, \& Marsolek, 1990; Hayes-Roth \& Thorndyke, 1979; Just \& Carpenter, 1978; Mandler \& Murachver, 1985; Potts, Keenan, \& Golding, 1988; Singer \& Ferreira, 1983). First, when two sentences need to be bridged, reading time for the second sentence in the sequence varies with its semantic distance from the first (Keenan, Baillet, \& Brown, 1984; Singer, 1979, Experiment 3). Second, after reading a text sequence (e.g., "The cat leapt up on the table. Fred picked up the cat and put it outside'), the sentences provide strong memory cues for one another. This supports the hypothesis that the reader has inferred a causal bridge between the two (Black \& Bern, 1981; Trabasso \& Sperry, 1985). Third, answer time is about equal for questions about certain inferential bridges of a message and for questions about comparable explicit message ideas (Singer, 1980; Singer \& Ferreira, 1983).

Because of their contribution to local text coherence, the failure to draw bridging inferences would seriously impede comprehension. Therefore, we set out to examine characteristics of the reader that predict individual differences in bridging-inference processes. The investigation emphasized two possible predictors of bridging. The first was the capacity of the reader's working memory. The second was the reader's predisposition to access pertinent world knowledge in the service of successful comprehension. We next examine the role of these traits in comprehension and inference processing.

\section{WORKING MEMORY AND COMPREHENSION}

Working memory serves as the workspace for computation and for the storage of currently active ideas (Baddeley, 1986; Baddeley \& Hitch, 1974; Carpenter \& Just, 1989; Daneman \& Carpenter, 1980; Perfetti \& Lesgold, 1977). ${ }^{1}$ The storage and processing requirements of lan- 
guage comprehension suggest a central role for working memory. In particular, both written and spoken messages require the analysis of lengthy sequences of symbols and the construction of numerous levels of form and meaning representation. Furthermore, information must be shared among these related endeavors (Carpenter \& Just, 1989).

Working-memory capacity ought to have a direct impact on successful bridging-inference processes. Consider again Example 1 above. Bridging will be facilitated if propositions underlying the first sentence still reside in working memory when the second sentence is examined. However, only relatively recent and important antecedent text ideas are likely to be stored in working memory at any time (Fletcher \& Bloom, 1988; Kintsch \& van Dijk, 1978). Other ideas, including some of those needed for bridging computations, must be reinstated from LTM to working memory. Memory reinstatement, furthermore, is a resource-demanding activity (Lesgold, Roth, \& Curtis, 1979). Therefore, readers with inefficient working memories are likely to be hampered in their inference processing.

The functional capacity of working memory can be evaluated with the reading span task, which emphasizes the tradeoff between the storage and processing functions of working memory (Daneman \& Carpenter, 1980). In the reading span task, people read sets of unrelated sentences and attempt to recall the final word of each sentence after each set. The relationship between reading span and language comprehension may be interpreted in terms of either the total activation capacity of working memory or the efficiency of computational processes (Daneman \& Carpenter, 1980; Daneman \& Tardif, 1987; Just \& Carpenter, 1992).

Reading span is correlated with standarized comprehension test scores, (e.g., verbal SAT and the Nelson-Denny), with pronoun resolution, and with the ability to answer factual questions (Daneman \& Carpenter, 1980, 1983). The relation between reading span and pronoun resolution is especially pertinent for the present study, because pronoun resolution, like bridging inference, requires the identification of text referents. Traditional measures of short-term memory, such as digit span and word span, in contrast, do not predict comprehension scores (e.g., Baddeley, Logie, Nimmo-Smith, \& Brereton, 1985; Daneman \& Carpenter, 1980, 1983; Dixon, LeFevre, \& Twilley, 1988).

Previous studies of the relationship between reading span and inference processing have focused on simple and complex deductions by readers (Dixon et al., 1988; Masson \& Miller, 1983). The results of these studies were equivocal. In both cases, reading span was significantly correlated with inference judgment accuracy. In neither case, however, did reading span account for unique variance in inference accuracy, once factors such as vocabulary knowledge and performance on explicit story ideas were taken into consideration. The present study differed from the earlier ones in its predominant, though not exclusive, focus on local bridging inferences. Although these inferences do not constitute complex problem solving (cf. Black \& Bower, 1980; Bloom et al., 1990), they are still difficult to achieve if crucial referents are absent from working memory.

\section{ACCESSING RELEVANT KNOWLEDGE IN COMPREHENSION}

The second predictor of inference processing was the reader's accessing of pertinent world knowledge during comprehension. Even the simple inference needed to bridge the sequence in Example 1 above depends on knowing the effect of fire on paper. The text ideas and the relevant knowledge must co-occur in working memory for bridging to result. There have been few attempts to examine the impact of individual differences in knowledge access on inference processing, although the role of readers' specialized knowledge has been documented (e.g., Anderson, Reynolds, Schallert, \& Goetz, 1976; Post, Greene, \& Bruder, 1982; Spilich, Vesonder, Chiesi, \& Voss, 1979).

Individual differences in access to world knowledge during comprehension are reflected by the integration task of Potts and Peterson (1985). This task presents threesentence paragraphs that relate several real and nonsense concepts, such as the one shown in Table 1. After selfpaced study of the paragraph, a series of questions is presented. Some of the questions can be answered correctly only with reference to relevant knowledge. For example, the answer to the question, "Is a pony larger than a CAZ?" depends on the knowledge that a pony is larger than a beaver. Accuracy on such items, called the access scale, ${ }^{2}$ constituted the index of knowledge access in comprehension. It is important that large individual differences on this measure have been documented (Potts, Keller, \& Rooley, 1981; Potts \& Peterson, 1985).

Potts and Peterson (1985) reasoned that the tendency to access pertinent knowledge in comprehension ought to promote the incorporation of novel text information with existing world knowledge. They quantified knowledge incorporation as the degree to which novel and familiar text ideas primed one another in a subsequent lexical decision

Table 1

Sample Paragraph and Questions From Integration Task Paragraph

A JAL is larger than a TOC.

A beaver is larger than a CAZ.

A TOC is larger than a pony.

True Test Questions

Access

A TOC is larger than a beaver.

A pony is larger than a CAZ.

Memory

A JAL is larger than a TOC.

Simple Inference

Real

A pony is larger than a beaver. 
task. Their finding of a systematic relationship between access and incorporation supported the validity of the access scale. In the present study, we used the access measure for a different purpose: namely, to predict the computation of bridging inferences. Because bridging inferences require access to relevant knowledge, successful bridging should vary directly with the tendency to invoke that knowledge.

In summary, the study was designed mainly to assess the impact on bridging-inference computation of (1) working-memory capacity and (2) the tendency to access world knowledge during comprehension. The general hypothesis was that people who are higher in reading span and on the access scale are more likely to compute bridging inferences during the course of comprehension.

Of primary interest were local bridging inferences about the consequences of an action. As discussed earlier, the coherence of Example 1 ("The spy quickly threw his report in the fire. The ashes floated up the chimney.) depends on a bridging inference such as, "The report burned to ashes." We considered these materials to be representative of the broader class of local bridging inferences in their dependence on working-memory capacity and on the availability of pertinent knowledge. In fact, research has revealed similar profiles of bridging-inference processing for probable consequences (Potts et al., 1988; Singer \& Ferreira, 1983), case-filling concepts (Singer, 1980), and cause-effect relationships (Black \& Bern, 1981; Keenan et al., 1984).

In this task, the subjects read texts of moderate length and then answered questions, some of which probed ideas that expressed the bridging inferences of interest. It was predicted that reading span and access would be positive predictors of inference accuracy and negative predictors of answer time. The latter prediction means that answer time will be faster for those readers who have computed the inferences of interest during comprehension.

The questions probed inferences that were derived from sentences either near or far apart in the text. For the text distances chosen, reading span should have a greater involvement in the far condition.

Under certain test conditions, people predominantly judge the plausibility of questioned facts, whether implied or even previously stated, rather than retrieving them from the text representation (Reder, 1982, 1987). In these circumstances, answer times do not reflect the text representation encoded during reading. To avoid this situation, inference test conditions were selected that, according to Reder, favor a "direct retrieval" strategy-namely, testing occurred shortly after reading and presented foil questions that were related to the stories. In addition, the first inference test story served as practice, to increase the likelihood that uniform strategies were used during the experimental test.

We also measured the reading times of the second sentences in the bridging-inference sequences. It is upon read- ing the second sentence that the bridging inference is required, which might result in elevated reading time. However, we did not entertain firm predictions about the relationships between the predictor variables and reading time. For example, high reading span might increase the likelihood that a bridge is computed and result in long reading time, or it might make more efficient an inference that most readers draw, and so be associated with short reading time.

Two additional stories and accompanying questions that probed deductive inferences were presented after the bridging-inference task. Consider, for example, the sequence: "The Spring Episode was the first revolution in Morinthia. All Morinthian revolutions were failures." The reader can deduce that the Spring Episode was a failure. The deductive-inference task was intended to permit a direct comparison between the present results and those of previous studies (Dixon et al., 1988; Masson \& Miller, 1983). In contrast with the bridging task, however, neither access nor reading span were confidently expected to influence deductive-inference processing. First, because the deductive inferences did not require access to world knowledge, access was not predicted to affect deductive-inference processing. Second, because the deductions were not essential to text coherence, they might not reliably accompany comprehension (Potts et al., 1988; Singer \& Ferreira, 1983). In this event, no systematic relationship between reading span and the inference measures would be expected.

The results of the deductive task confirmed that neither reading span nor access accounted for unique variation in deductive-inference accuracy. Insofar as this outcome replicates previous findings (Dixon et al., 1988; Masson \& Miller, 1983), the deductive task will not be considered further in this treatment. ${ }^{3}$

\section{METHOD}

To assess the predictions, four tests were administered. Workingmemory capacity was evaluated with the reading span task (Daneman \& Carpenter, 1980). Knowledge access was measured using Potts and Peterson's (1985) integration task. Bridging-inference processing was measured using a timed question-answering task (Singer \& Ferreira, 1983). Finally, the Nelson-Denny Reading Test (Brown, Bennett, \& Hanna, 1981) was administered to provide standardized measures of vocabulary knowledge and comprehension.

The study took the form of two experiments, which provided generally consistent data. Because they used identical methods except for the examination of the deductive inferences, they have been combined in this presentation.

\section{Subjects}

The participants were 149 introductory psychology students at the University of Manitoba, who took part for course credit. They were all native speakers of English.

\section{Materials}

Reading span test. The reading span materials were constructed from a pool of 100 unrelated sentences (10-14 words each), se- 
lected from books encompassing a wide range of topics. Forty-six of the sentences were randomly selected, in order to construct 14 sets of sentences for the test. There were five sets of two sentences and three sets each of three, four, and five sentences. A test list was constructed that presented the sets in ascending order of size. The first two two-sentence sets constituted practice. Table 2 shows a sample set of four sentences.

Each sentence set was followed by a cloze item (Masson \& Miller, 1983). Cloze items were constructed by randomly selecting one of the sentences and randomly deleting two of its content words. The cloze test was included to ensure that the participants were not simply memorizing the last words of the sentences. Table 2 shows the cloze item of one sentence set.

The Nelson-Denny Reading Test. Form E of the Nelson-Denny Reading Test was used. The vocabulary subtest consisted of 100 multiple-choice items and took $15 \mathrm{~min}$ to complete. The comprehension test consisted of eight passages and a total of 36 corresponding multiple-choice questions and took $20 \mathrm{~min}$ to complete.

Integration task. The integration task materials consisted of six brief paragraphs, each of which linked several nonsense and real concepts. For each paragraph, there were 18 test sentences. One passage was presented earlier, in Table 1 . Integrating the concepts of that paragraph results in the linear ordering, $J A L>T O C>$ pony $>$ beaver $>C A Z$.

Each paragraph was followed by four categories of test sentence: (1) Access items, of greatest interest in this study, required access to relevant world knowledge (e.g., the verification of "A TOC is larger than a beaver" requires coupling the paragraph statement, "A TOC is larger than a pony," with the knowledge that a pony is larger than a beaver); (2) memory items, such as "A JAL is larger than a TOC," tested ideas presented directly in the paragraph; (3) simple inference items, such as "A JAL is larger than a pony," presented ideas that could be logically deduced from the paragraph, but did not require access to pertinent knowledge; and (4) real items, such as "A pony is larger than a beaver," were statements linking the real concepts.

The first paragraph constituted practice, and the resulting data were disregarded. For each passage, there were nine true and nine false test items. In the true category, there were four access, one simple inference, one real, and three memory test items. The nine false test items were constructed by reversing the concepts in the true sentences, yielding items such as, "A beaver is larger than a pony." Access scores were based on the eight access items, four true and four false.

Inference task. Inference processing was assessed using the bridging-inference task. The materials consisted of six passages and corresponding questions, adapted from those of Singer and Ferreira (1983). Table 3 presents part of one of the passages, plus several questions. Each passage consisted of 19 sentences, including four "target" sentences that were designed to induce the computation of bridging inferences. In the near inference condition, the target followed immediately after its antecedent. Consider the sequence: "Then she found that the milk was three weeks old. The smell turned

Table 2

Sample Sentence Set From the Reading Span Task

\section{Sentences}

After the storm had subsided we broke camp and departed. Many students do not believe that homework is a good idea. The one great stumbling block was the lack of capital.

The following day the patient asked for a bedside telephone.

Correct Answer

departed idea capital telephone (in any order)

Cloze Item

The one great

block was the lack of
Table 3

Partial Story and Corresponding Questions From Bridging-Inference Task

\section{Passage}

Carol was getting very irritated. (Explicit)

She forgot about the meat she was broiling. (Antecedent)

Carol heard the dog barking upstairs. (Intervening)

Somehow a bird had gotten trapped in the bathroom. (Intervening)

She released the creature and trudged back down. (Intervening)

Smoke was pouring from the oven. (Far bridging-inference target)

Carol wondered what could happen next. (Explicit)

Then she found that the milk was three weeks old. (Antecedent)

The smell turned her stomach. (Near bridging-inference target)

She threw everything out and went to McDonald's. (Explicit)

Sample Questions

Was the milk sour? (Near bridging inference)

Did the meat burn? (Far bridging inference)

Did Carol become irritated? (Explicit)

Did Carol eat the dinner? (Negative explicit)

her stomach." Upon reading the target, "The smell turned her stomach," one needs to find a referent for "smell." This is achieved by drawing a bridging inference, such as "The milk spoiled and produced a bad smell." In the far inference condition, three sentences intervened between the target sentence and its antecedent (see Table 3). The serial positions of the near and far inference sequences were randomized across the five experimental stories. The first passage constituted practice and consisted of only 11 sentences.

It has been estimated that readers retain approximately two micropropositions and four macropropositions in working memory (e.g., Kintsch \& van Dijk, 1978; Vipond, 1980). Therefore, the intervening sentences of the far bridging condition would likely eliminate some of the propositions of the antecedent sentence from working memory. However, the predictions depended only on the ability of the high-span readers to retain, on the average, more propositions of the antecedent sentences than could the low-span readers.

Eight questions followed each passage in a fixed random order. There was one question about each bridging inference, for a total of two near and two far questions per passage. Two "explicit" questions addressed ideas that were stated directly in the passage. Finally, two "negative" questions likewise probed directly stated ideas, but required the answer "no."

\section{Procedure}

The experiment consisted of two sessions. The first was conducted with groups of about 25 participants, who were tested on the reading span and Nelson-Denny tests. In the second session, the participants were tested individually on the integration and inference tests. Each session took approximately $1 \mathrm{~h}$.

In the reading span task, each sentence was displayed for $8 \mathrm{sec}$, using slides. The participants were instructed to read each sentence carefully. The end of a set of sentences was signaled by a blank slide and by the experimenter's prompt, "recall." Then, the participants had $12 \mathrm{sec}$ to write the last word of each sentence of the set in their answer booklets. Next, a slide showed the cloze item for that set. The participants had another $12 \mathrm{sec}$ to recall the two deleted content words. The booklets had a separate blank page for each set of sentence-final words and another for the cloze item of each set. After each 12-sec answer period, the experimenter stated, "Turn the page." The test continued in this fashion until all 14 sets had been viewed.

The Nelson-Denny test was administered using the standard instructions accompanying the test, except that reading rate was not measured. 
In the second session, the materials of the integration and inference tasks were viewed on a computer-controlled monochrome monitor. The subjects responded by pressing a ready button with the preferred thumb and yes and no buttons, which were randomly assigned to the left and right index fingers.

During the integration task, upon viewing the "ready" signal, the participant pressed a ready button to view a paragraph. Following Potts and Peterson (1985, p. 112), the instructions encouraged the participants to use relevant world knowledge to understand the paragraph. After self-paced study, the participant pressed the ready button to view the test items for that paragraph. On each test trial, a fixation point appeared for $1 \mathrm{sec}$, followed by the test item. There was an answer time limit of $6 \mathrm{sec}$, and a wrong answer was credited if no response was made. There was a 4-sec interstimulus interval between questions and a 10-sec interval separating the last question about one paragraph and the "ready" signal initiating the next trial.

In the inference task, the participants read brief stories, each of which was followed by a set of questions. Upon viewing a "ready" signal, the participant pressed the ready button. After a 500 -msec presentation of a fixation point, the participant used the ready button to self-pace the presentation of each sentence. Sentence-reading time was recorded as the time between ready-button presses.

The end of a story was signaled by the message, "The End." Five seconds later, a fixation point was presented for $500 \mathrm{msec}$, followed by the first question about that story. The participants responded "yes" or "no" to each question; wrong answers were credited if a 6-sec time limit was exceeded. The interquestion interval was $3 \mathrm{sec}$. The eight questions of each story were presented in a fixed random order. Five seconds after the last question of a story disappeared, the "ready" signal indicated that the next story could be viewed.

\section{Summary of Variables}

Reading span was measured both in terms of total words recalled (Baddeley et al., 1985; Dixon et al., 1988; Masson \& Miller, 1983) and in terms of reading span "size" (Daneman \& Carpenter, 1983). The maximum score for total words was 42 . Reading span size is the largest set size $(2,3,4$, or 5$)$ for which a subject scored perfectly on at least two of the three sets. ${ }^{4}$ The maximum score for the cloze component of the reading span test was 24 (four sizes $\times$ three sets per size $\times$ two words per cloze item).

The Nelson-Denny Reading Test included vocabulary and comprehension components, based on 100 and 36 items, respectively. The integration task (Potts \& Peterson, 1985) yielded accuracy measures for access, memory, simple inference, and real test items.

The bridging-inference task yielded accuracy and answer-time scores for near and far inference questions. It also generated accuracies and answer times for the "yes" explicit items, and target inference reading time in the near and far conditions.

\section{Design}

The focus on individual differences favored the presentation of the same materials in the same order to all subjects. As a result, the design differed from those of typical experimental studies of inference processes. For example, the inference materials were not cycled systematically across conditions (i.e., explicit, and near and far inference), the timed measures were not evaluated with reference to comparable explicit times, and there were no explicit "target" sentences in the text. This approach could be taken because the study was not designed to show that readers draw local bridging inferences. Rather, it was assumed that they do, on the basis of the extensive evidence reviewed earlier. Although a counterbalanced design for this problem could have been devised, it would have required a prohibitive number of participants.

\section{RESULTS}

Twelve of the 149 participants generated incomplete data, and 2 others misunderstood the reading span test. Therefore, most analyses used $n=135$. The reading-time analyses excluded the data of 2 more subjects, whose mean target reading time exceeded all others' by more than $10 \mathrm{sec}$.

Table 4

Descriptive Statisties $(n=135)$

\begin{tabular}{lrrrr}
\hline \multicolumn{1}{c}{ Measure } & $M$ & $\begin{array}{c}\text { Standard } \\
\text { Deviation }\end{array}$ & Range & $\begin{array}{r}\text { Maximum } \\
\text { Possible }\end{array}$ \\
\hline $\begin{array}{lrrrr}\text { Reading span } \\
\quad \text { Total words }\end{array}$ & 31.5 & 11.2 & $19-42$ & 42 \\
$\quad$ Size & 3.2 & 1.2 & $1.5-5$ & 5 \\
$\quad$ Cloze & 9.6 & 3.7 & $0-18$ & 24 \\
Nelson-Denny & & & & 100 \\
$\quad$ Vocabulary & 59.6 & 17.3 & $18-99$ & 36 \\
$\quad$ Comprehension & 23.3 & 14.7 & $8-34$ & \\
Integration Task (\%) & & & & \\
$\quad$ Access & 81.0 & 17.5 & $38-100$ & \\
$\quad$ Memory & 84.7 & 14.4 & $33-100$ & \\
$\quad$ Inference & 84.1 & 18.4 & $20-100$ & \\
$\quad$ Real & 88.1 & 16.3 & $30-100$ & \\
Inference Accuracy (\%) & & & & \\
$\quad$ Explicit Bridging & 96.2 & 8.5 & $40-100$ & \\
$\quad$ Near Bridging & 92.0 & 10.4 & $50-100$ & \\
$\quad$ Far Bridging & 88.8 & 10.4 & $40-100$ & \\
Inference Answer Time (milliseconds) & & & & \\
$\quad$ Explicit Bridging & 2195 & 373 & $1,421-3,786$ & \\
$\quad$ Near Bridging & 2049 & 403 & $1,280-3,977$ & \\
$\quad$ Far Bridging & 2211 & 392 & $1,384-3,499$ & \\
Inference Reading Time (milliseconds) & & & & \\
$\quad$ Near Bridging* & 3168 & 1133 & $1,287-8,473$ & \\
Far Bridging* & 3373 & 1136 & $1,408-8,131$ & \\
\hline
\end{tabular}

$*_{n}=133$. 
Table 5

Correlation Matrix

\begin{tabular}{|c|c|c|c|c|c|c|c|c|c|c|c|}
\hline Variable & 1 & 2 & 3 & 4 & 5 & 6 & 7 & 8 & 9 & 10 & 11 \\
\hline \multicolumn{12}{|l|}{ Reading Span } \\
\hline 1. Total words & - & & & & & & & & & & \\
\hline \multicolumn{12}{|l|}{ Nelson-Denny } \\
\hline 2. Vocabulary & $.23^{*}$ & & & & & & & & & & \\
\hline 3. Comprehension & $.29 *$ & $.64 *$ & & & & & & & & & \\
\hline \multicolumn{12}{|l|}{ Integration task } \\
\hline 4. Access & .14 & $.32 *$ & $.29 *$ & & & & & & & & \\
\hline \multicolumn{12}{|l|}{ Bridging-Inference Accuracy } \\
\hline 5. Explicit & .17 & .15 & .12 & $.26^{*}$ & & & & & & & \\
\hline 6. Near & .12 & .21 & .10 & $.23^{*}$ & $.23^{*}$ & & & & & & \\
\hline 7. Far & $.31^{*}$ & $.31^{*}$ & .18 & $.42 *$ & $.46^{*}$ & $.29 *$ & & & & & \\
\hline \multicolumn{12}{|l|}{ Bridging-Inference Answer Time } \\
\hline 8. Explicit & .15 & $-.28 *$ & $-.36^{*}$ & -.17 & $-.32 *$ & -.16 & -.12 & & & & \\
\hline 9. Near & .10 & $-.33 *$ & $-.30 *$ & -.18 & $-.36^{*}$ & -.07 & -.16 & $.64^{*}$ & & & \\
\hline $\begin{array}{l}\text { 10. Far } \\
\text { Bridging-Inference Reading Time }\end{array}$ & .05 & $-.31 *$ & $-.28^{*}$ & -.16 & $-.32 *$ & -.19 & -.03 & $.65^{*}$ & $.71^{*}$ & & \\
\hline 11. Near & -.04 & -.14 & -.11 & $.25 *$ & .12 & 11 & .09 & $.23^{*}$ & .16 & $.27 *$ & \\
\hline 12. Far & -.03 & -.12 & -.13 & $.22 *$ & .13 & .12 & .10 & $.25^{*}$ & .19 & $.31 *$ & $.91 *$ \\
\hline
\end{tabular}

\section{Descriptive Statistics}

Descriptive statistics for each variable are presented in Table 4. Table 5 shows intercorrelations among those variables that bear on the main hypotheses. Correlations for variables examined for the purpose of task validation (e.g. , the nonaccess scales of the integration task) do not appear in Table 5, but they will be discussed in the text. The correlation coefficients are evaluated using the relatively conservative $\alpha$ level of .005 .

Reading span. The total-words measure of reading span was highly correlated with reading span size $(r=$ .76). We adopted the total-words measures for the sake of comparability with other investigations of inference processing (Dixon et al., 1988; Masson \& Miller, 1983). In the remainder of this paper, reading span will refer to the total-words measure.

Reading span was significantly correlated with the cloze component of that task $(r=.31)$. This indicates that cloze task performance was not traded off against the memorization of sentence-final words. In that event, a negative correlation between the two measures would have been detected.

Correlations among the predictor variables. Both of the Nelson-Denny scales were significantly correlated with reading span and access, the predictors of greatest theoretical concern. Furthermore, Nelson-Denny comprehension and vocabulary were highly correlated $(r=.64)$, a value similar to that measured by Dixon et al. (1988).

Finally, the correlation between reading span and access was not significant $(r=.14)$. This is an important outcome, because it indicates that reading span and access reflect different characteristics of the reader. This conclusion is consistent with Whitney and Waring's (1991) finding that reading span is, if anything, inversely related to the use of pertinent knowledge in the computation of local elaborative inferences.

Inference measures. Reading span and access were positively correlated with the bridging-inference accuracy measures. While the access correlations were consistently significant, reading span was significantly correlated only with far bridging accuracy.

The bridging inference answer times were, as expected, negatively correlated with many of the other measures, but their correlations involving reading span and access were not significant. Finally, access was significantly positively correlated with reading time for the bridginginference target sentences, and reading span was not.

Integration task. The integration task correlations are shown in Table 6. It is important that the real measure correlated only .13 with memory and .24 with inference. These values are much smaller than the other four correlations in Table $6(M=.63, S D=.04)$. This is the expected pattern, because knowledge about the real terms, such as pony and beaver, ought to play no role in accuracy on memory and inference items. Potts and Peterson (1985) reported negligible values for these two correlations. Therefore, the integration task was functioning in the manner that we intended.

\section{Regression Analyses}

Multiple linear regression analyses were applied to the data. Reading span, access, and their interaction functioned as predictors. Nelson-Denny vocabulary was also included as a predictor variable, because vocabulary knowledge constitutes a central component of reading comprehension (e.g., Baddeley et al., 1985; Carpenter \& Just, 1989; Dixon et al., 1988).

Table 6

Correlation Matrix for Integration Task

\begin{tabular}{lccc}
\hline Predictor & Access & Memory & Inference \\
\hline Access & & & \\
Memory & $.59^{*}$ & & \\
Inference & $.61^{*}$ & $.66^{*}$ & \\
Real & $.66^{*}$ & .13 & $.24^{*}$ \\
\hline
\end{tabular}

${ }^{*} p<.01$. 
Table 7

Standardized Regression Coeficients for Analyses Inspecting the Effect of the Reading Span $\times$ Access Interaction on Bridging-Inference Processing

\begin{tabular}{|c|c|c|c|c|c|c|c|c|}
\hline \multirow[b]{2}{*}{ Predictor } & \multicolumn{3}{|c|}{ Accuracy } & \multicolumn{3}{|c|}{ Answer Time } & \multicolumn{2}{|c|}{ Reading Time } \\
\hline & Explicit & Near & Far & Explicit & Near & Far & Near & Far \\
\hline Reading Span & $1.31 *$ & -.13 & $1.08 *$ & $-1.53 *$ & $-.90 \dagger$ & -.62 & -.22 & -.37 \\
\hline Access & $1.90^{*}$ & -.10 & $1.57^{*}$ & $-2.15^{*}$ & $-1.33 \dagger$ & $-1.15+$ & .07 & -.18 \\
\hline Reading Span $\times$ Access & $-2.21^{*}$ & .37 & $-1.61 \dagger$ & $2.71^{*}$ & $1.65 \dagger$ & 1.40 & .34 & .63 \\
\hline Nelson-Denny Vocabulary & .07 & .13 & $.16 \dagger$ & $-.26 *$ & $-.32 *$ & $-.33^{*}$ & $-.24 *$ & $-.22 *$ \\
\hline$R^{2}$ & $.16^{*}$ & $.08 \dagger$ & $.30 *$ & $.20^{*}$ & $.16^{*}$ & $.15^{*}$ & $.12 *$ & $.10 \dagger$ \\
\hline
\end{tabular}

The results of the regression analyses are shown in Table 7. For accuracy and answer time, reading span and access were significant predictors in most conditions. Equally important, the reading span $\times$ access interaction was significant in a majority of the conditions. For reading time, Nelson-Denny vocabulary was the only significant predictor. ${ }^{5}$

The significant reading span $\times$ access interactions for accuracy and answer time were probed by separate regression analyses for individuals of low (0-28 words), medium (29-33 words), and high (34-42 words) reading span. Access and Nelson-Denny vocabulary were the predictors, but the main concern was whether access was significant for the different groups. Table 8 shows that access was significant in most conditions for low-readingspan subjects, but in only one condition each for the medium- and high-span subjects. In addition, it was only for far accuracy that access was at least marginally significant for all three groups.

\section{DISCUSSION}

Several features of the regression analyses support the involvement of reading span and knowledge access in bridging-inference processing. First, reading span and access accounted for significant accuracy and answer-time variance in most of the conditions. As predicted, high reading span and access scores were generally associated with high accuracies and fast answer times. Second, for accuracy, though not for answer time, reading span and access affected inference processing mainly in the far condition.

Table 8

Standardized Regreasion Coefficients (SRCs) of Access as a Predictor of Bridging-Inference Processing as a Function of Reading Span

\begin{tabular}{|c|c|c|c|c|c|c|c|}
\hline \multirow[b]{3}{*}{ Measure } & \multirow[b]{3}{*}{ Condition } & \multicolumn{6}{|c|}{ Reading Span } \\
\hline & & \multicolumn{2}{|c|}{ Low } & \multicolumn{2}{|c|}{ Medium } & \multicolumn{2}{|c|}{ High } \\
\hline & & SRC & $\overline{R^{2}}$ & SRC & $R^{2}$ & SRC & $R^{2}$ \\
\hline \multirow[t]{3}{*}{ Accuracy } & Explicit & .34 & $.12^{*}$ & -.10 & .01 & .19 & .03 \\
\hline & & .19 & .03 & .29 & .07 & .13 & .02 \\
\hline & Far & .47 & $.26^{*}$ & .34 & $.10 \dagger$ & .28 & $.07 \ddagger$ \\
\hline \multirow[t]{3}{*}{ Answer Time } & Explicit & -.35 & $.12 *$ & .02 & .00 & .20 & .04 \\
\hline & Near & -.27 & $.08 \ddagger$ & .16 & .03 & .04 & .00 \\
\hline & Far & -.32 & $.10 \dagger$ & .18 & .03 & .02 & .00 \\
\hline
\end{tabular}

${ }^{*} p<.01 . \quad \dagger p<.05 . \quad \ddagger p<.10$.
Third, the analyses revealed informative interactions between reading span and access: Access accounted for significant variance predominantly for low-reading-span subjects and for the far inference accuracy measure. One interpretation of these patterns involves a compensatory mechanism. High access would compensate for the absence from working memory of a referent by providing the understander with more, though not all, of the building blocks needed to bridge the current propositions to the message representation. This would benefit lowreading-span subjects in all conditions and all readers in the far inference condition. A second interpretation of the interactions entails an expanded view of access: It states that access may address the predisposition to retrieve pertinent text information as well as world knowledge. Only readers who reinstate essential referents that have been purged from working memory will have the opportunity to bridge them.

It is important for these interpretations that several features of the results of Potts and Peterson (1985) and of the present study converge to support the validity of the access scale. First, Potts and Peterson documented a dissociation between the scales of the integration task: The incorporation of new text information with general knowledge was systematically predicted by the access scale, and, equally important, not by the memory and inference scales. Second, Potts and Peterson found that, as predicted, the memory and inference scales were negligibly correlated with performance on real facts. Third, if performance on access items (e.g., "A TOC is larger than a beaver.") depended only on memory for the nonsense paragraph, then access and memory scores should be about equal. However, over numerous experiments, access scores were systematically lower than memory scores (Potts \& Peterson, 1985). Fourth, our data replicated both the correlation and the absolute performance results mentioned in the latter second and third points. These findings justify the present interpretation of the access scores. Conversely, these patterns contradict the possibility that the access scale simply measures the reader's effort to perform the integration task. ${ }^{6}$

Nelson-Denny vocabulary was a negative predictor of all of the timed measures. Reading span and access, in contrast, were not significant predictors of reading time. It is noteworthy, however, that the latter predictors were more strongly associated with far than near inference read- 
ing time and that their contributions had the same interactive pattern that was observed for inference answer time. This suggests that on-line measures, such as reading time, may prove to be informative measures in further studies of individual differences in inference processing.

Some of the measured relationships, such as some of the regression $R^{2}$ values and the reading span correlations, were of modest magnitude. However, the $R^{2}$ values were generally within the range of .17 to .45 reported for inference measures by Dixon et al. (1988) and Masson and Miller (1983). In addition, the subjects' near-ceiling accuracy on the inference questions may have contributed to the relatively small correlation values. The results suggest that some variability in inference computation may not be able to be captured by individual differences.

\section{On-line or Retrieval Inferences?}

As discussed earlier, the proposal that causal bridging inferences typically accompany comprehension was, on the basis of extensive evidence, assumed rather than tested in this study. The focus on individual differences, on the other hand, implies that there are some constraints on successful bridging. It is useful, therefore, to examine some features of the data that bear on the assumption of online bridging.

One result that is inconsistent with the assumption of on-line inference computation is that reading span and access were not stronger predictors of far inference answer time than of near inference answer time. Insofar as answer time is a more faithful index of on-line inference than is accuracy (Singer, 1979), the present pattern discourages strong conclusions about the locus of inference.

Second, Table 5 shows that the correlations between inference reading time and answer time were positive. It may be argued that, if the bridging inferences accompanied reading, these values should have been negative. That is, on-line bridging ought to increase reading time, with a concomitant reduction of answer time. However, it is likely that the positive correlations resulted from the contribution to both the timed measures of people's reading speed, a stable reader characteristic that is only moderately related to comprehension ability (Palmer, MacLeod, Hunt, \& Davidson, 1985).

Other features of the data, in contrast, are consistent with on-line bridging. First, access correlated positively with reading time and negatively with answer time. This is the pattern that would result if the predisposition to access pertinent knowledge promoted on-line bridging processes. Second, and more importantly, when explicit accuracy was added as a predictor in the regression analysis of far inference accuracy, reading span and access retained their status as significant, positive predictors (see Note 5). This discourages the analysis that high reading span and access merely ensure the encoding of explicit text ideas, which then serve as input to retrieval inference processes. In conclusion, because the results were not uniformly consistent with the hypothesis that the causal inferences accompanied comprehension, future individual difference studies might build in direct tests of this hypothesis.

\section{Predictors of Inference Processing}

Next, we address the mechanisms by which the main predictor variables contribute to bridging-inference performance. First, the involvement of working memory was treated in detail earlier. Most briefly, bridging inferences require the identification of a referent for at least one of the current text propositions. The crucial referent is more likely to be available for readers with large workingmemory capacities.

Second, accessing relevant information promotes the co-occurrence in working memory of the pertinent knowledge needed for a bridging inference. Again, consider the sequence: "The spy quickly threw his report in the fire. The ashes floated up the chimney." Some pertinent facts might include, "Reports are made of paper" and "Burning paper produces ashes." The co-occurrence of related propositions in working memory may result in the bridging of those propositions (e.g., Bloom et al., 1990).

More specifically, pertinent knowledge may be accessed in order to validate the ideas that bridge text propositions (Singer, Halldorson, Lear, \& Andrusiak, in press; Singer, Revlin, \& Halldorson, 1990). In this regard, consider the sequence: "Frank took an aspirin. His headache went away." The reader must infer the bridge that the first event caused the second. This bridge can be validated by retrieving pertinent information such as, "Aspirin relieves headaches." Consistent with this analysis, such questions as, "Does aspirin relieve headaches?" are answered more quickly after passages in which they validate bridging inferences than after control passages (Singer et al., in press; Singer et al., 1990).

Third, vocabulary knowledge was a positive predictor of far inference accuracy and was inversely related to inference answer time and bridging target reading time. Dixon et al. (1988) attributed the correlation between vocabulary and reading speed (Palmer et al., 1985; but see Baddeley et al., 1985) predominantly to the rate of word recognition. More specific to inference computation is the fact that processing the meanings of familiar words may place fewer demands on the limited resources of working memory. This may promote the manipulation and comparison of those meanings-operations that likely contribute to bridging - and facilitate other bridging computations that do not directly involve the manipulation of word meaning.

Word familiarity may also directly enhance reading span (Dixon et al., 1988). However, we propose that word familiarity makes a unique contribution to inference processing: Holding constant the capacity of working memory, inferential computations are hypothesized to be more readily applied to more familiar meanings than to less familiar ones.

Finally, the data revealed that reading span and access affected accuracy and answer times for explicit as well as implied text ideas. How might this come about? Greater working-memory capacity would permit more text propositions to be retained across processing cycles. This would result in more propositions being stored in LTM (Kintsch \& van Dijk, 1978). Access would enhance memory for 
explicit ideas if high-access readers are more likely to appropriately reinstate those ideas to working memory during reading. This is consistent with the possibility, discussed earlier, that high-access readers retrieve pertinent text ideas as well as world knowledge when they are needed.

It is concluded that the predisposition to access pertinent knowledge during comprehension and large workingmemory capacity promote the computation of local bridging inferences. The data indicate that these two reader characteristics are distinct from one another. Further research will be needed to specify how access, reading span, and vocabulary knowledge collaborate to guide inference processing. Progress in this realm may suggest techniques of remediation for readers who exhibit impoverished comprehension processes.

\section{REFERENCES}

Anderson, J. R. (1983). The architecture of cognition. Cambridge, MA: Harvard University Press.

anderson, R. C., Reynolds, R. E., Schallert, D. L., Goetz, E. T. (1976, July). Frameworks for comprehending discourse (Tech. Rep. No. 12). Urbana-Champaign, IL: University of Illinois, Laboratory for Cognitive Studies in Education.

Baddeley, A. D. (1986). Working memory (Oxford Psychology Series Vol. 11). Oxford: Clarendon.

BADDELEY, A. D., \& HrTCH, G. (1974). Working memory. In G. Bower (Ed.), The psychology of learning and motivation (Vol. 8, pp. 47-89). New York: Academic Press.

BAdDeley, A. D., Logie, R., Nimmo-Smith, I., Brereton, N. (1985). Components of fluent reading. Journal of Memory \& Language, 24, 119-131.

Black, J. B., BerN, H. (1981). Causal inference and memory for events in narratives. Joumal of Verbal Learning \& Verbal Behavior, 20, 267-275.

BLACK, J. B., \& BowER, G. H. (1980). Story understanding as problem solving. Poetics, 9, 223-250.

Bloom, C. P., Fletcher, C. R., van den Broek, P., Reitz, L., \& Shapiro, B. P. (1990). An on-line assessment of causal reasoning during comprehension. Memory \& Cognition, 18, 65-71.

Brooks, L. R. (1968). Spatial and verbal components of the act of recall. Canadian Journal of Psychology, 22, 349-367.

Brown, J. I., Bennett, J. M., Hanna, G. (1981). Nelson-Denny Reading Test. Chicago: Riverside.

CARPENTER, P. A., \& JUSt, M. A. (1989). The role of working memory in language comprehension. In D. Klahr \& K. Kotovsky (Eds.), Complex information processing: The impact of Herbert A. Simon (pp. 31-68). Hillsdale, NJ: Erlbaum.

DANEMAN, M., CARPENTER, P. A. (1980). Individual differences in working memory and reading. Journal of Verbal Learning \& Verbal Behavior, 19, 450-466.

DANEman, M., CARPenter, P. A. (1983). Individual differences in integrating information between and within sentences. Journal of $E x$ perimental Psychology: Leaming, Memory, \& Cognition, 9, 561-583.

DANEMAN, M., \& TARDIF, T. (1987). Working memory and reading skill re-examined. In M. Coltheart (Ed.), Attention and Performance $X I I$. London: Erlbaum.

Dixon, P., LeFevre, J., \& TWilley, L. C. (1988). Word knowledge and working memory as predictors of reading skill. Journal of Educational Psychology, 80, 465-472.

Fletcher, C. R., Bloom, C. P. (1988). Causal reasoning in the comprehension of simple narratives. Journal of Memory \& Language, 27, 235-244.

Fuetcher, C. R., Hummel, J. E., \& Marsolek, C. J. (1990). Causality and the allocation of attention during comprehension. Journal of Experimental Psychology: Leaming, Memory, \& Cognition, 16, 233-240.

Haviland, S. E., Clark, H. H. (1974). What's new? Acquiring new information as a process in comprehension. Journal of Verbal Learning \& Verbal Behavior, 13, 512-521.

HAYES-Roth, B., ThORNDYKe, P. W. (1979). Integration of knowledge from text. Journal of Verbal Learning \& Verbal Behavior, 18, 91-108.

Just, M. A., C CARPENTER, P. A. (1978). Inference processes during reading: Reflections from eye fixations. In J. Senders \& $R$. Monty (Eds.), Eye movements and the higher psychological functions (pp. 195207). Hillsdale, NJ: Erlbaum.

Just, M. A., CARPENTER, P. A. (1992). A capacity theory of comprehension: Individual differences in working memory. Psychological Review, 99, 122-149.

Keenan, J. M., Baillet, S. D., Brown, P. (1984). The effects of causal cohesion on comprehension and memory. Journal of Verbal Leaming \& Verbal Behavior, 23, 115-126.

Kintsch, W., \& VAN DiJK, T. A. (1978). Toward a model of text comprehension and production. Psychological Review, 85, 363-394.

LesGold, A. M., Roth, S. F., CuRTIS, M. E. (1979). Foregrounding effects in discourse comprehension. Journal of Verbal Leaming \& Verbal Behavior, 18, 291-308.

MANDler, J. M., MURAchyer, T. (1985, November). Script activation and lexical processing. Paper presented at the annual meeting of the Psychonomic Society, Boston.

Masson, M. E. J., \& Miller, J. A. (1983). Working memory and individual differences in comprehension and memory of text. Journal of Educational Psychology, 75, 314-318.

Palmer, J., Macleod, C. M., Hunt, E., \& Davidson, J. E. (1985). Information processing correlates of reading. Journal of Memory \& Language, 24, 59-88.

Perfetti, C. A., \&esgold, A. M. (1977). Discourse comprehension and sources of individual differences. In $M$. Just \& $P$. Carpenter (Eds.), Cognitive processes in comprehension (pp. 141-183). New York: Wiley.

Post, T. A., Greene, T., Bruder, G. (1982, November). "On-line" text processing in high-and low-knowledge individuals. Paper presented at the annual meeting of the Psychonomic Society, Minneapolis.

Potrs, G. R., Keenan, J. M., * Golding, J. M. (1988). Assessing the occurrence of elaborative inferences: Lexical decision versus naming. Joumal of Memory \& Language, 27, 399-415.

PotTs, G. R., KELler, R. A., \& ROOLEY, C. J. (1981). Factors affecting the use of world knowledge to complete a linear ordering. Journal of Experimental Psychology: Human Learning \& Memory, 7 , 254-268.

Potts, G. R., \& Peterson, S. B. (1985). Incorporation versus compartmentalization in memory for discourse. Joumal of Memory \& Language, 24, 107-118.

REDER, L. M. (1982). Plausibility judgments versus fact retrieval: Alternative strategies for sentence verification. Psychological Review, 89, 250-280.

REDER, L. M. (1987). Strategy-selection in question answering. Cognitive Psychology, 19, 90-134.

Singer, M. (1979). Processes of inference in sentence encoding. Memory \& Cognition, 7, 192-200.

SINGER, M. (1980). The role of case-filling inferences in the coherence of brief passages. Discourse Processes, 3, 185-201.

Singer, M., Ferreira, F. (1983). Inferring consequences in story comprehension. Journal of Verbal Leaming \& Verbal Behavior, 22, 437-448.

Singer, M., Halldorson, M., Lear, J. C., Andrusiak, P. (in press). Validation of causal bridging inferences. Journal of Memory \& Language.

Singer, M., Revin, R., \&Alidorson, M. (1990). Bridging-inference and enthymeme. In A. Graesser \& G. Bower Eds., The psychology of learning and motivation (Vol. 25, pp. 35-51). New York: Academic Press.

Spiluch, G. J., Vesonder, G. T., Chiesi, H. L., Voss, J. F. (1979). Text processing of domain-related information for individuals with 
high and low domain knowledge. Joumal of Verbal Leaming \& Verbal Behavior, 18, 275-290.

Trabasso, T., \& SPERRY, L. L. (1985). Causal relatedness and importance of story events. Journal of Memory \& Language, 24, 595-611.

TURNER, M. L., ENGLE, R. W. (1989). Is working memory capacity task dependent? Journal of Memory \& Language, 28, 127-154.

VIPOND, D. (1980). Micro- and macroprocesses in text comprehension. Journal of Verbal Learning \& Verbal Behavior, 19, 276-296.

Whitney, P., WARING, D. A. (1991). The role of knowledge in comprehension: A cognitive control perspective. In G. Simpson (Ed.), Understanding word and sentence (pp. 199-216). Amsterdam: Elsevier.

\section{NOTES}

1. Working memory, as it pertains to the present issues, will be viewed as distinct from a visuospatial working memory (Anderson, 1983; Baddeley et al., 1985; Brooks, 1968; Daneman \& Tardif, 1987; Turner \& Engle, 1989). This position is compatible both with the hypothesis of separate verbal and spatial working memories and with Baddeley's (1986) proposal of a visuospatial system guided by a central executive system dedicated to processing and temporary storage.

2. Although Potts and Peterson referred to people's score on these items as their "integration" score, it is clear that they interpreted this index as one of knowledge access (Potts \& Peterson, 1985, p. 110).
We will therefore call this scale the access measure, which forms the central component of Potts and Peterson's "integration task."

3. A report of the analysis of the deductive-inference task is available from the first author.

4. Furthermore, if all three sets at this level were correct, then the subject was credited with an additional half point (.5), if one set at the next higher level was correct (Daneman \& Carpenter, 1983). If the criterion was not achieved even for two-sentence sets, the subject received a score of 1 if none of the two-sentence sets were correct and a score of 1.5 if one of those was correct.

5. In another set of regression analyses, explicit accuracy was added as a predictor of inference processing. It is particularly important that explicit accuracy was a significant predictor of far inference accuracy but that it did not alter the pattem or significance of the contributions of reading span, access, and reading span $\times$ access.

6 . To examine the possible impact of some subjects' lack of effort, we recomputed the correlation coefficients (Table 5), discarding the data of 6 individuals who obtained the unlikely scores of $50 \%$ or lower on the real subscale of the integration task. However, most of the correlation coefficients changed by .03 or less.

(Manuscript received December 18, 1990; revision accepted for publication December 14, 1991.)

\section{Fifth Annual International Conference of The Society for the Advancement of Socio-Economics (SASE) New York City March 26-28, 1993}

\section{Call for Papers}

The Fifth Annual International Conference of the Society for the Advancement of SocioEconomics (SASE) will be held in New York City, March 26-28, 1993. The theme of the conference is Incentives and Values as Foundations of Social Order.

John Kenneth Galbraith (Harvard Univesity) and Robert Heilbroner (New School for Social Research) are among the featured speakers.

Specific topics will include Markets and Democracy in Eastern Europe and Latin America, War and Conversion, Health Care, Ethics, Decision Making, Endogenous Growth, The Environment, Risk Taking, Micro and Macro Socio-Economics, and Gender Issues in the Workplace.

SASE is a group of academic scholars, policy makers, and business people devoted to the development of new theoretical and methodological frameworks which explain economic and more general choice behavior. Premised upon the belief that economic behavior is not an isolated, abstract phenomenon, socio-economics draws upon the disciplines of psychology, sociology, political science, philosophy, and history in an attempt to recognize the complexity of human decisionmaking processes, and to locate economic behavior within a philosophical, historical, institutional, and ethical context.

Those interested in presenting a paper, organizing a session, or learning more about SASE should write to $714 \mathrm{H}$ Gelman Library, $2130 \mathrm{H}$ Street NW, Washington, DC 20052 (phone, 202944-8167; FAX, 202-994-1639). 